\title{
Development of Taste and Odor Sensing Technologies together with Sensors and Materials
}

\author{
Kiyoshi Toko* \\ Institute for Advanced Study, Research and Development Center for Five-Sense Devices, Kyushu University, \\ 744 Motooka, Nishi-ku, Fukuoka 819-0395, Japan
}

It was a hot summer day in July 1991, 27 years ago, when I headed to Noda Campus of Tokyo University of Science from Narita Airport. I had attended an international conference on colloids held in Compiègne, France, in the middle of July and returned to Japan to attend a workshop on electricity held at Tokyo University of Science. It is often said that eastward air travel is exhausting because the airplane arrives at the destination in the morning. This is really true. I felt really sleepy after the airplane landed in Japan. As soon as I arrived at the hotel in Noda, Chiba, I went to my room and bed without eating.

I was able to get enough rest during the night, and the next morning, I gave a presentation on taste sensors at Tokyo University of Science. Only two years had passed since I applied for the patent on taste sensors and no practical taste sensors were available in those days. The performance of taste sensors at that time was very poor and could not compare with that of today's taste sensors. Looking back, it was daring of me to give a presentation on such taste sensors. I was young then (38 years old).

Anyway, I was not asked any difficult questions after my presentation and I attended the workshop until the last day. After the workshop, I headed to Haneda Airport to return to Fukuoka. On the train to Haneda Airport, I met Professor Tetsuro Nakamura by chance. It was my first meeting and conversation with Professor Nakamura. He also attended the workshop and complimented me, saying “Taste sensors have already been completed, haven't they?" I realized that taste sensors were, in fact, incomplete and just replied "Not really, but thank you". I talked with him about trivial topics on the train and we each headed homeward.

Note that 1991 was an especially meaningful year for me. At the international conference held in France, I remembered that there were somewhat sardonic responses from the audience to my presentation; that is, the research was hard to understand. However, several years since then, a female researcher who attended that conference spoke to me and said "I was surprised that a Japanese researcher is carrying out such unique research". I was really flattered by what she said.

The relationship between Professor Nakamura and I did not end on the train. I received a telephone call from him immediately after I had met him on the train. He said "I'm an Editor of Sensors and Materials. Could you please organize a special issue on taste and odor sensors?" I instantaneously considered it to be beyond my ability, but Professor Nakamura was really

*Corresponding author: e-mail: toko@ed.kyushu-u.ac.jp https://doi.org/10.18494/SAM.2018.1953 


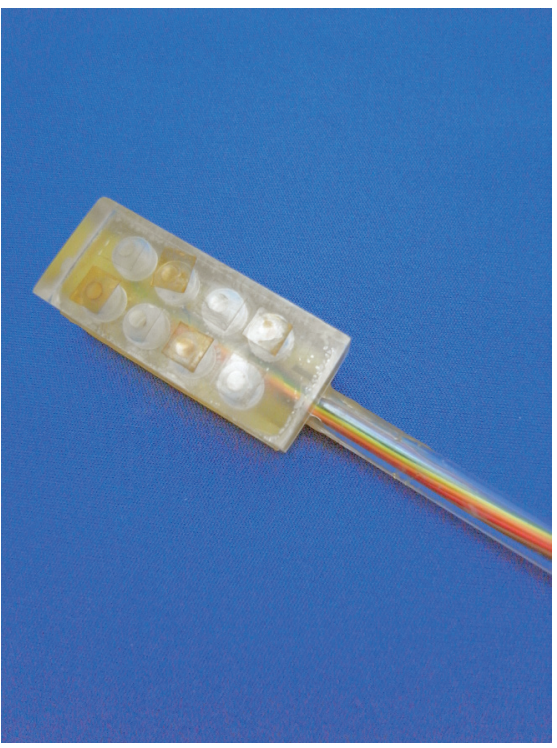

(Color online) Photo of electrode of early taste sensor.

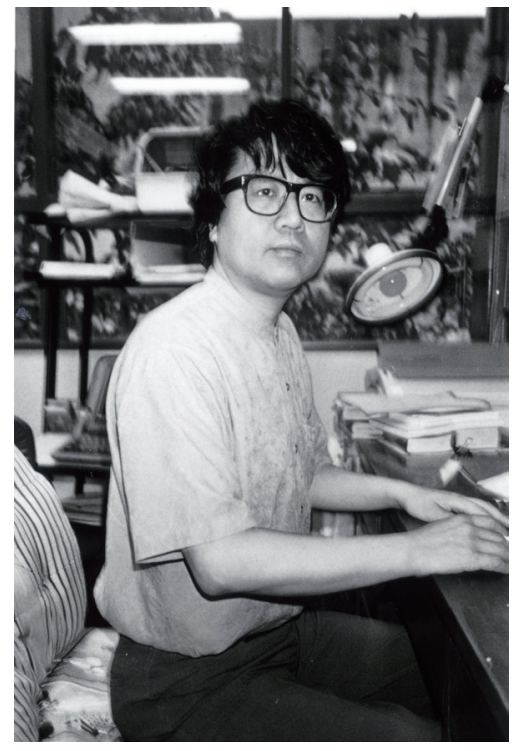

Photo of myself (about 40-years old).

enthusiastic. Because my policy is not to decline requests from others, I tentatively accepted his request.

After that, hardships began. I called my friends affiliated with the Institute of Electrical Engineers of Japan, the Institute of Electronics, Information and Communication Engineers, and the Japanese Society of Applied Physics, of which I was a member, and asked them to submit papers to the special issue. At that time, the now ubiquitous Internet service that enables us to send e-mails to many destinations at once was not available. I believe that special issues were very rare at that time, although they are common today. I'm surprised by Professor Nakamura's foresight, that is, his recognition of the importance of special issues.

In this way, I served as a guest editor of three special issues, Nos. 1-3, Vol. 4 (1992) entitled "Special Issue on Taste and Odor Sensors". Seventeen papers were included in these special issues. The range of areas of specialty of the authors was varied. Researchers in the fields of not only chemical sensors and biosensors but also physiology and biochemistry submitted papers to these special issues. I'm really grateful to those researchers who willingly (I believe) submitted papers. I also served as a guest editor of two special issues in 1995. After that, I requested my research colleagues to serve as guest editors of special issues on taste and odor sensors.

As my efforts have been appreciated, a section on Biosensors and Related Areas was established in 2002 in Sensors and Materials. I assumed the post of Section editor in 2003 and have been held this post since then.

The advantage of Sensors and Materials that I appreciate most is that it provides an English proofreading service of submitted papers. In 2000, I published a book titled "Biomimetic Sensor Technology" from Cambridge University Press. In preparing the book, English 
correction by the proofreading service provided by Sensors and Materials was really helpful. I cited papers published in Sensors and Materials on numerous pages in the book.

These days, the publication of special issues is really popular in other journals. Also, in Sensors and Materials, the number of special issues on international conferences held in Asian countries has been increasing, which is a really favorable direction. I also would like to acknowledge the extraordinary effort of the staff of the publisher MYU in searching for guest editors.

Sensors and Materials has been developing steadily and is celebrating its 30th anniversary in 2018. Former and current editors and those who contributed to the development of Sensors and Materials have submitted 30th anniversary commemorative articles, which has made me feel nostalgic. Sensors and Materials has grown with the support of these people.

I wish both Sensors and Materials and the publisher MYU, led by President Yuji Hazeyama, continued outstanding success, and hope for further development of scientific technology in Japan and overseas, as well as for the happiness of people throughout the world. 